\title{
An Econometric Model of an Episode of Mental Health Care for Patients with Mild Conditions: Implications for Caregiver Substitution
}

\author{
JOHN G. CROSS,' DAVID J. KNESPER ${ }^{2}$ and J. PAUL DE ROOIJ' \\ 'Department of Economics and 'Department of Psychiatry, Mental Health Research Institute, \\ The University of Michigan, 205 Washtenaw Place, Ann Arbor, MI 48109-0720, U.S.A.
}

\begin{abstract}
This article presents a model of the number of hours of mental health care, the concurrent improvement in the patient's condition, the probability the patient will receive medications, and the reasons for treatment termination. The variables related to these aspects of mental health care are analyzed separately for patients of psychiatrists, psychologists, and social workers. Estimates of the average length of treatment, the average price and income elasticities, and the average cost of treatment are obtained from the model. The major conclusions from this study are that psychiatrists do not have a benefit-cost advantage in the treatment of relatively mild conditions, and that consumer responsiveness to variations in price appear to be largely confined to the decision to seek treatment. These and other findings provide a basis for making tentative recommendations about personnel substitution and reimbursement policies in mental health.
\end{abstract}

\section{INTRODUCTION}

This study develops a multi-equational model of an episode of mental health care using disaggregated data that describe individual patients and those who care for them. The model permits the study of the durations of treatment found in actual episodes of clinical care and takes into account the concurrent improvement in the patient's condition, the use of medications, and the reasons for termination of care. Three major groups of mental health specialists are considered: psychiatrists, psychologists, and social workers. These professionals have overlapping expertise, especially in the treatment of patients with less severe mental and emotional conditions [11], and they spend the bulk of their time working with these cases [13]. Accordingly, the model is applied to patients with these milder conditions.

The estimated coefficients in the model are used first to make various interprovider comparisons. Then, we calculate the effects of provider fees and patient income on the number of treatment hours provided by each specialist group. This second analysis provides some indication of the extent to which specialists modify their clinical practices in response to financial variables as well as perceptions of clinical need. Last, the model is used to simulate the care that patients who are receiving care from one provider group might expect to receive if services had been provided by a different group. This simulation allows for productivity comparisons across the three types of providers.

Taken together, these analyses enable us to address questions pertaining to the possibilities of provider substitution in mental health. The model also allows us to obtain overall estimates of the average cost of treatment, the average improvement per unit of input, and the elasticities of the hours of treatment with respect to fees, insurance, and patient income. Our results lead us to the conclusion that it may be possible to reallocate many patients who are now under the care of psychiatrists to psychologists and social workers, obtaining improvements in cost performance without loss in the quality of care. This article ends with a discussion of the broader implications of our findings for planning the personnel and reimbursement attributes of the mental health care provision system. 


\section{RELEVANT LITERATURE}

The influence of single variables on duration of treatment has been the subject of several studies. Pope et al. [22]. Balch et al. [2], and Carpenter and Range [4] considered the effect of patient fees, while May [19] studied the role of the patient's sex. Sue et al. [25] and Silverman and Beech [24] included treatment termination and other variables in their analysis of duration of treatment. The first efforts by economists to use detailed patient-level data to study duration of treatment include those of McGuire [20], Keeler et al. [9]. and Manning et al. [17]. McGuire used data provided by a national sample of psychiatrists describing up to their last ten patients treated, and concluded that the demand for psychiatric services was about twice as elastic as the demand for general medical services. By analyzing data from the Rand Health Insurance Study, Keeler et al. [9] came to a similar conclusion, as did Taube et al. [26] using data from the 1980 National Medical Care Utilization and Expenditure Survey. In another recent Rand study, Manning et al. [17] considered the decision to seek treatment in relationship to its cost. They found that the out-of-pocket price of medical care affects consumer decisions to seek care and decisions about the amount of care to purchase.

These studies have their limitations. The most serious are attributable to shortcomings in available data resources and to econometric problems caused by missing cxplanatory variables or truncated dependent variables [27]. For example, despite the large number of enrollees in the Rand Health Insurance Study, very few received mental health services. For this reason, Keeler and Wells and their colleagues were unable to distinguish between various diagnostic and provider groups; nor were they able to take into account a variety of other treatment characteristics. This present study uses a data set that describes, in rich detail, the characteristics of mental health care. Our data source enables us to construct an elaborate econometric model that overcomes some of the limitations of previous work and allows us to consider previously unanswered research questions.

\section{DATA AND METHODS}

\section{Mental Health Service Providers Survey}

Data describing the independent practices of mental health specialists and the treatment they provide to individual adult patients come from the Mental Health Service Providers Survey that has been described extensively elsewhere [15]. Briefly, during 1982 and 1983, nationally representative samples of psychiatrists, psychologists, and social workers received questions about themselves and about entire episodes of face-to-face care they provided to their last five patients who terminated treatment. $\dagger$ Of 4536 potential respondents, $66 \%$ returned valid questionnaires. One-third of the respondents did not report on five patients; consequently, data are available on approx. 6500 care episodes. Information obtained from a telephone survey of a sample of all respondents strongly indicated that patients were reported according to the instructions given. Concerning respondents who underreported, perceptions of burden generally prevented reporting more patients. A variety of reasonable, comparative procedures found no statistically significant differences attributable to patient reporting.

Several studies were carried out to help establish the accuracy, reliability, and representativeness of the survey data $[11,12,14,15]$. These studies all indicated that the survey data describe, with reasonable accuracy and consistency, the clinical activities and the characteristics of care provided

\footnotetext{
t The larger, overall project sample was divided so that one half received questions about terminated patients and the other half received questions about continuing patients. Data on continuing patients are necessarily censored; these data are not used in the study described here because we wished to model the entire treatment experience. We did a series of regressions to compare the continuing with the terminated patient data to determine whether patient characteristics differed by sample type. We found continuing patients, on average, to have been in treatment much less time and to have slightly more severe conditions (because continuing patients have not progressed so far through treatment). Variables critical to our present study (e.g. the patient's initial severity, income, age, insurance coverage, etc.) were not statistically different by sample type. Both samples were well represented by patients treated briefly or for very long periods. Continuing patients are a marginally more chronic group, but this difference is not close to being statistically significant. For another study, we have worked with the continuing patient data to infer expected length of treatment. We found that continuing patients are associated with out-referrals and treatment drop-outs, making for a shorter mean expected length of treatment. Nevertheless, our preliminary analysis of the continuing patient data that pertains to mild conditions tends to be consistent with the results of the present study.
} 
by mental health specialists who belong to large professional associations. These data are likely not representative of professionals belonging to small subspeciality societies for psychoanalysis. behavioral medicine, forensic work, etc.

This data set has the advantage of being large enough to support pruning to remove inappropriate data points that might lead to erroncous estimates and still leave subsamples large enough for reasonable econometric estimation. Accordingly, the data set was restricted in several ways. The total number of patient observations was reduced by $30 \%$ when patients with severe disorders (i.e. major depression, mania, schizophrenia and schizophreniform disorder) were excluded. Of the remaining cases, $30 \%$ were incomplete, missing data of relevance to the current study. In order to avoid giving unduly heavy weight to the behavior of providers who had two or more patients with the same diagnosis, one patient was selected at random whenever the respondent reported multiple patients with the same diagnosis. This procedure further reduced the size of the data set, but it did not introduce a new bias because random patient selection was not applied significantly more to one provider group than to another.

We compared the characteristics of patients who entered our sample with those that were discarded for any reason, and found no statistically significant differences between the two groups. We are aware of no persuasive reason to expect that in deleting portions of the original data set in order to improve the representativeness of the sample, new errors might have been introduced.

Regarding some of the survey's specific questions, the duration of treatment refers to the total number of treatment hours the patient received from the provider; it summarizes an uninterrupted series of visits that the provider considers to comprise an entire treatment episode. Our survey methods prevented us from using definitions [8] that include treatment received from all providers or that define episodes delimited by some arbitrary break (e.g. minimum three months complete remission before a new treatment episode begins). Nevertheless, our measure has the advantage of being the one used for reimbursement purposes and in actual clinical practice. Because respondents were asked to report patients for whom they alone were primarily responsible, it is unlikely that other providers were involved in any major way.

Only two diagnostic clusters were considered. "Relationship problems" is a category that applies to patients having problems with marriage partners, family, peers, or similarly placed individuals. These conditions are not mental disorders, but are often the focus of professional attention and treatment. The second cluster contains all patients with anxiety, neurotic (including mild depressive neuroses), and personality disorders. By limiting our analysis to patients with relatively mild disorders, the possibility of systematic differences between patients is minimized. For example, it is unlikely that patients with relationship problems seen by psychiatrists will differ significantly on clinical characteristics from similar patients seen by psychologists and social workers. Moreover, a series of statistical comparisons (e.g. age, sex, severity, reason for discontinuing treatment) across providers and the two diagnostic clusters did not identify significant differences.

The initial and final severity of all these conditions were measured using a simplified version of the Global Assessment Scale [6] that ranges from 1 (unable to function) to 100 (superior functioning). This scale has become one of the major components in the latest Diagnostic and Statistical Manual of Mental Disorders [1], making it, perhaps, the most widely used in mental health and ideal for a study concerned with provider substitution.

Diagnostic category and condition severity both summarize what are certainly multidimensional patient characteristics. The test of our simplifications ultimately rests on the quality of the statistical analyses they support. In a study using these diagnostic and severity measures, Knesper et al. [14] found that there were no significant differences among provider groups in their ability to estimate a severity level or to select a consistent condition classification of a standardized patient.

"Drugs" refers to known psychoactive agents in the case of psychiatrists and to any recognized drug in the case of the other provider groups. Definitions that differ by provider group were necessary because psychiatrists treat most of their patients with some form of drug (primarily psychoactive agents), whereas nonphysician providers use fewer drugs and report over-the-counter medicines. No single definition would be statistically useful for both groups. Termination of treatment was defined as "normal" if the provider judged the treatment to be completed. In this case, the dummy termination variable was given a value of 1 . Referrals, no shows, and other forms of termination were all given the variable value of 0 . 
Table 1. Variable list

\begin{tabular}{|c|c|}
\hline Variable name & Description \\
\hline $\begin{array}{l}\text { Endogenous variables } \\
\text { 1. LOT* } \\
\text { 2. IMPROV* } \\
\text { 3. DRUG* } \\
\text { 4. TERM* }\end{array}$ & $\begin{array}{l}\text { Estimate of the length of an episode of care measured as the total number of hours of treatment with the } \\
\text { same provider for a mental condition } \\
\text { Change in the severity of the mental condition until termination of treatment. The severity scale was obtained } \\
\text { from Endicott et al. [6] } \\
\text { Dummy variable indicating the use of drugs in treatment. (See text for definition) } \\
\text { Dummy variable indicating the reason for termination of treatment. } 1=\text { the patient terminated treatment } \\
\text { after obtaining some or maximum treatment benefits. } 0=\text { all other reasons }\end{array}$ \\
\hline 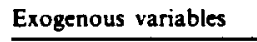 & \\
\hline $\begin{array}{l}\text { 5. TOT \# PAT } \\
\text { 6a. PRIOFF } \\
\text { 6b. PUBLIC } \\
\text { 7. FEE\%INC } \\
\text { 8. PATAGE* } \\
\text { 9. PATSEX* } \\
\text { 10. PATINCOM* } \\
\text { 11. PATINP\%* } \\
\text { 12. ISEV* } \\
\text { 13. AVMINVIS* } \\
\text { 14a. NFEE* } \\
\text { 146. FEE\%PATY } \\
\text { 15. INSUR\%* } \\
\text { 16. TOT\%NEU } \\
\text { 17. PROEXPER } \\
\text { 18. PRO\%PSYCH } \\
\text { 19. PROSEX }\end{array}$ & 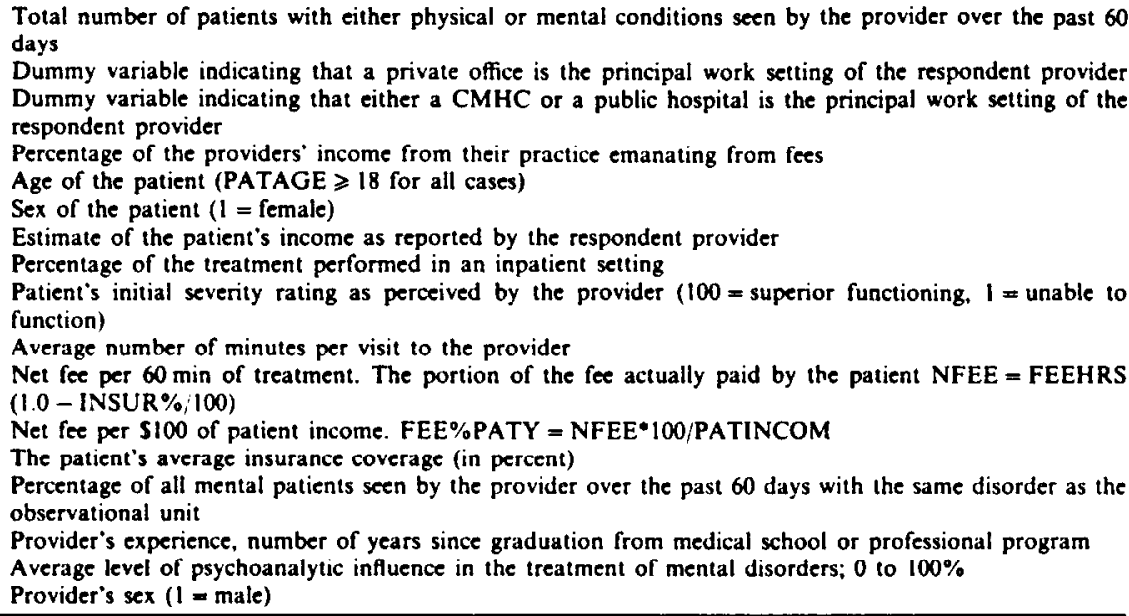 \\
\hline
\end{tabular}

All the variable names with an asterisk suffix come from the last five-patient section of the survey. The remaining variables come from the sections of the survey eliciting general information about the provider's practice.

In responding to survey questions about a patient's insurance coverage, providers recorded the average rate of insurance (from both public institutional and private insurance sources) that was available to defray or subsidize the cost of care. Knesper and Pagnucco [12] studied a subsample of providers to ascertain the accuracy of this level of detail. Respondents in this subsample were asked to compare their records with the data they reported in the questionnaire; it was found that the two corresponded quite closely. Studies preliminary to the actual survey had indicated that more detailed insurance data would not be sufficiently accurate for analytical purposes; accordingly, additional insurance data were not collected. $\dagger$

The remaining variables are listed and defined in Table 1. Table 2 reports their sample statistics.

\section{Model specification}

Our previous work [10] took the accepted position that patients do not consume visits to their care providers per se; instead, they seek to purchase improvements in health status. Accordingly, hours of treatment and improvement in health status are modelled simultaneously in this study. The use of drugs and the reason for termination also are treated as endogenous because the perceived change in health status affects these treatment variables (and vice versa). However, the model does not permit duration of treatment to affect the reason for treatment termination, since, otherwise, the model could not be estimated [16]. Table 3 contains the specification of the model; selected features of each equation are discussed below.

The first equation associates hours of treatment with patient and provider characteristics, change in health status, and the reason for treatment termination. In principle, both patient and provider play a role in determining hours of treatment, while the level of fees probably influences the preference of both parties. We assume here, however, that the effect of out-of-pocket expenses on patients is more important. For this reason, we include net fee (and, implicitly, insurance coverage)

+Patients in our data set could have self-selected into certain insurance plans, and that could introduce bias into our analysis. Several regressions were run between insurance coverage and initial patient severity; no statistically significant relationships were found, suggesting self-selection is not an important consideration. We do not have data to determine if insurance affected the patient's choice of provider; therefore, our results are conditional on the type of provider. This caveat applies also to our simulation procedures described later in the text. 
Table 2. Sample statistics

\begin{tabular}{|c|c|c|c|c|c|c|}
\hline \multirow[b]{2}{*}{ Variable } & \multicolumn{2}{|c|}{ Psychiatrists } & \multicolumn{2}{|c|}{ Psychologists } & \multicolumn{2}{|c|}{ Social workers } \\
\hline & Mean & SD & Mean & SD & Mean & SD \\
\hline \multicolumn{7}{|c|}{ Anxiety, neurotic and personality disorders [NEURO] } \\
\hline $\begin{array}{l}\text { LOT } \\
\text { TERM }\end{array}$ & $\begin{array}{r}62.85 \\
0.64\end{array}$ & $\begin{array}{r}191.35 \\
0.48\end{array}$ & $\begin{array}{r}39.55 \\
0.62\end{array}$ & $\begin{array}{r}100.84 \\
0.49\end{array}$ & $\begin{array}{r}28.45 \\
0.68\end{array}$ & $\begin{array}{r}45.17 \\
0.47\end{array}$ \\
\hline IMPROV & 19.12 & 19.20 & 20.01 & 16.45 & 18.89 & 16.60 \\
\hline DRUG & 0.22 & 0.42 & 0.11 & 0.31 & 0.15 & 0.36 \\
\hline TOT $\#$ PAT & 92.34 & 96.96 & 51.56 & 46.38 & 54.12 & 49.41 \\
\hline MEDSCH & 0.09 & 0.28 & 0.04 & 0.21 & 0.03 & 0.16 \\
\hline PRIOFF & 0.67 & 0.47 & 0.83 & 0.38 & 0.57 & 0.50 \\
\hline PUBLIC & 0.13 & 0.33 & 0.06 & 0.23 & 0.22 & 0.42 \\
\hline FEE\%INC & 67.83 & 41.19 & 80.42 & 35.67 & 55.64 & 46.20 \\
\hline PATAGE & 36.68 & 12.32 & 34.63 & 9.27 & 35.82 & 10.24 \\
\hline PATSEX & 0.61 & 0.49 & 0.63 & 0.48 & 0.74 & 0.44 \\
\hline PATINCOM & 33,355 & 77,760 & 28,421 & 24,908 & 23,829 & 24,095 \\
\hline PATINP\% & 9.51 & 27.17 & 4,90 & 20.38 & 5.62 & 21.66 \\
\hline ISEV & 50.40 & 16.96 & 50.37 & 15.09 & 50.21 & 15.03 \\
\hline NFEE & 43.83 & 53.13 & 31.32 & 26.08 & 23.87 & 19.21 \\
\hline FEE\%PATY & 0.87 & 2.49 & 0.37 & 0.67 & 0.24 & 0.25 \\
\hline INSUR\% & 50.05 & 38.25 & 50.07 & 37.38 & 39.92 & 41.17 \\
\hline TOT $\%$ NEU & 55.08 & 27.37 & 72.55 & 22.91 & 73.66 & 25.42 \\
\hline PROEXPER & 15.35 & 9.69 & 15.09 & 7.87 & 15.97 & 7.90 \\
\hline PRO\%PSYCH & 55.20 & 29.35 & 42.64 & 29.34 & 56.31 & 26.19 \\
\hline PROSEX & 0.86 & 0.35 & 0.75 & 0.43 & 0.38 & 0.49 \\
\hline AVMINVIS & 47.16 & 13.67 & 52.88 & 8.63 & 52.34 & 8.40 \\
\hline$N$ & 174 & & 363 & & 152 & \\
\hline \multicolumn{7}{|c|}{ Relationship problems [RELAT] } \\
\hline LOT & 20.52 & 32.56 & 19.61 & 36.01 & 21.53 & 43.78 \\
\hline TERM & 0.74 & 0.44 & 0.65 & 0.48 & 0.72 & 0.45 \\
\hline IMPROV & 18.81 & 17.49 & 16.13 & 15.37 & 13.75 & 13.38 \\
\hline DRUG & 0.15 & 0.36 & 0.02 & 0.15 & 0.05 & 0.22 \\
\hline TOT \#PAT & 88.00 & 84.19 & 56.32 & 52.11 & 51.30 & 43.96 \\
\hline MEDSCH & 0.06 & 0.23 & 0.03 & 0.17 & 0.02 & 0.15 \\
\hline PRIOFF & 0.75 & 0.43 & 0.86 & 0.35 & 0.49 & 0.50 \\
\hline PUBLIC & 0.09 & 0.29 & 0.04 & 0.19 & 0.23 & 0.42 \\
\hline FEE\%INC & 71.69 & 40.72 & 83.54 & 32.76 & 50.31 & 47.10 \\
\hline PATAGE & 36.74 & 11.49 & 35.38 & 11.18 & 35.21 & 10.74 \\
\hline PATSEX & 0.49 & 0.50 & 0.55 & 0.50 & 0.65 & 0.48 \\
\hline PATINCOM & 43.981 & 105,323 & 35,926 & 65,157 & 26,932 & 44,733 \\
\hline PATINP\% & 4.91 & 17.43 & 3.23 & 17.27 & 3.72 & 17.14 \\
\hline ISEV & 60.98 & 17.48 & 60.09 & 15.72 & 99.63 & 16.30 \\
\hline NFEE & 40.51 & 32.83 & 32.23 & 25.50 & 21.51 & 19.81 \\
\hline FEE\% \%ATY & 0.41 & 0.90 & 0.33 & 0.54 & 0.33 & 0.73 \\
\hline INSUR \% & 51.93 & 36.34 & 49.07 & 36.22 & 42.00 & 41.95 \\
\hline TOT\%NEU & 54.42 & 25.58 & 73.76 & 20.83 & 72.91 & 25.76 \\
\hline PROEXPER & 17.03 & 9.83 & 14.43 & 7.39 & 16.76 & 8.79 \\
\hline PRO\%PSYCH & 55.04 & 28.40 & 37.25 & 27.49 & 51.38 & 25.67 \\
\hline PROSEX & 0.82 & 0.39 & 0.73 & 0.44 & 0.33 & 0.47 \\
\hline AVMINVIS & 48.03 & 9,79 & 53.69 & 9.63 & 54.02 & 8.24 \\
\hline$N$ & 89 & & 279 & & 138 & \\
\hline
\end{tabular}

but not gross fee in the first equation. Another assumption is that the experience of improvement will result in longer treatment encounters, whereas lack of improvement will lead to out-referrals. Our overall approach to change in health status is discussed elsewhere [10].

The second equation models improvement (i.e. change in severity) in the patient's condition. This equation includes some provider characteristics, such as the number of years in practice and the extent of experience with patients of the same diagnosis group, on the grounds that providers with relatively more of these qualities are likely to be more effective. An interaction term between drugs

Table 3. Model specification

\begin{tabular}{|c|c|}
\hline $\begin{array}{l}\text { Equation } \\
\text { number }\end{array}$ & Equation \\
\hline (1) & $\begin{array}{l}\text { In(LOT) }=\alpha_{1}+\alpha_{2} \text { IMPROV }+\alpha_{1} \text { TERM }+\alpha_{4} \text { PATINCOM }+\alpha_{3} \text { PATINP } \%+\alpha_{1} \text { NFEE }+\alpha_{7} \text { TOT } \text { PAT }+\alpha_{1} \text { PRIOFF } \\
\quad+\alpha_{9} \text { PUBLIC }+\alpha_{10} \text { FEE } \% \text { INC }+\alpha_{11} \text { PROSEX }+\alpha_{32} \text { PRO } \% \text { PSYCH }+c_{1}\end{array}$ \\
\hline (2) & $\begin{array}{l}\text { IMPROV }=\beta_{1}+\beta_{2} \text { LOT }+\beta_{3} \text { LOT }^{2}+\beta_{4} \text { DRUG }+\beta_{3} \text { DRUG } I S E V+\beta_{6} \text { PATAGE }+\beta_{7} \text { PATINP } \%+\beta_{8} \text { TOT } \% \text { NEU } \\
\quad+\beta_{8} \text { PROEXPER }+\beta_{10} \text { ISEV }+\epsilon_{2}\end{array}$ \\
\hline (3) & $\begin{array}{l}\ln (D)=\gamma_{1}+\gamma_{2} \text { PATAGE }+\gamma_{3} \text { PATAGE }+\gamma_{4} \text { TOT } \# \text { PAT }+\gamma_{3} \text { PUBLIC }+\gamma_{6} \text { PRO } \% \text { PSYCH }+\gamma_{7}(E(I M P R O V \mid D R U G-1) \\
-E(\text { IMPROVIDRUG }=0))\end{array}$ \\
\hline (4) & $\ln (T)=\delta_{1}+\delta_{2}$ DRUG $+\delta_{3}$ PATSEX $+\delta_{4}$ FEE $\%$ PATY $+\delta_{1}$ AVMINVIS $+\delta_{2}$ PRIOFF + $\delta_{7}$ PRIOFF ISEV \\
\hline
\end{tabular}


and initial severity is included because it is likely that drugs are less effective for relatively healthy patients.

The third equation deals with the probability of drug use. The total number of patients under the care of one provider is included because providers with large caseloads are more likely to dispense drugs, making drugs a substitute for more time-intensive counseling. Older patients and those treated in public settings are likely to receive more drugs because older patients are more likely to have recurrent conditions and public settings, in general, rely more on drugs than on counseling. Therefore, variables reflecting these clinical relationships are also included. Finally, we introduce the expected productivity of drug treatment by including terms that equal the expected level of improvement with drugs minus the expected level of improvement without drugs. This value is obtained from the expected value of the improvement equation, and it is through this variable that the model accounts for the simultaneity between drugs and the variables in the first two equations. We hypothesize that drug treatments should increase with an expected positive productivity of drugs. This general method is fully explained in Schmidt [23].

The final equation concerns the reason for termination. Such events as unilateral terminations or referrals most certainly depend on a number of diagnostic and personal variables that are not available to us. We are able to include the patient's income, insurance coverage, and other variables, but clearly this is not a completely satisfactory description of the termination decision. This equation is not stochastically linked to the other equations in the model because we sought to avoid an overly complex model specification.

\section{Econometric considerations}

The model contains the following standard assumptions:

$$
\begin{aligned}
& {\left[\begin{array}{l}
c_{j} \\
c_{i}^{2}
\end{array}\right] \sim N\left(\left[\begin{array}{l}
0 \\
0
\end{array}\right],\left[\begin{array}{l}
\sigma_{11} \sigma_{12} \\
\sigma_{21} \sigma_{22}
\end{array}\right]\right), \quad \sigma_{i j} \neq 0 \quad \forall i, j,} \\
& E\left[c_{i}^{\prime} \epsilon_{j}^{\prime}\right]=E\left[c_{i}^{2} c_{j}^{2}\right]=E\left[c_{i}^{\prime} \epsilon_{j}^{2}\right]=0 \quad \forall i \neq j, \\
& E\left[X_{i} \epsilon_{j}\right]=0 \quad \forall i, j,
\end{aligned}
$$

(where $X$ represents any exogenous variable)

$$
\begin{aligned}
& E\left[\operatorname{DRUG}_{i} c_{j}\right]=0 \quad \forall i, j, \\
& E\left[\operatorname{TERM}_{i} c_{j}\right]=0 \quad \forall i, j .
\end{aligned}
$$

These are conventional assumptions; discussions of their acceptability are found in, for example, Schmidt [23] and Maddala [16]. The last two assumptions may be unrealistic; however, dropping them would require a much more extensive and complex model.

The model is nonlinear and was estimated by extremizing the concentrated likelihood function, using a nonlinear optimization program [21]. The standard errors were obtained from the estimated information matrix, except for the last equation which was estimated independently. $\dagger$

Since respondents sometimes reported more than one patient with the same diagnosis, we selected one patient at random. This procedure guarantees independent observations. The specification was determined by testing the model using the discarded observations. To avoid pretest bias, the final model was estimated once.

Following model estimation, inter-provider comparisons were made using a Montc-Carlo method suggested by Mariano and Brown [18]. We adapted their method in order to generate overall estimates that are representative of the provider's caseload. Briefly, we divided the data into provider and patient variables; we then sampled with replacement from these sets, and substituted the values into our model together with the generated random deviates to obtain estimates of the treatment characteristics. Many of the variables in the model are dummy variables, and for the

\footnotetext{
†All standard errors used in this article come from the directly estimated Hessian matrix in compliance with the recommendations of Cramer [5]. Several starting points were used to determine if the same results would be obtained. In all cases the results were very similar. A procedure described by Goldfeld and Quandt [7] was then implemented to check for muttiple solutions. That is, the functional specification of the duration of treatment and production function equations imply that in the (LOT,IMPROV) space there will only be one intersection of the curves.
} 
Monte-Carlo method to work properly, it was necessary to generate binary values in some way; the use of average values would be improper. The method of sampling with replacement is intended to deal with this problem in a way that will generate estimates of the overall treatment characteristics. The estimates of the hours of treatment are in logarithmic form; however, we did not attempt to make any adjustment to take this transformation into account. Finally, to obtain estimates of the cost of treatment, the duration estimates were multiplied by the gross fee.

\section{Caveats}

The current study has the following possible major limitations. The reader is asked to keep them in mind when considering the subsequent portions of this article.

We have no assurance that gradations in the GAS reflect equal intervals in some fundamental diagnostic sense. Thus, improvement on one part of the scale may not be directly comparable to improvement on another. Because the recall period varies for respondents, a related concern may be that the validity and reliability of the GAS measure may vary with time in treatment.

Although a previous study [14] supports the assumption of uniform patient evaluations across provider groups, our procedures do not guarantee them. This is particularly troublesome when considering providers' differential effectiveness. It is possible that some providers perceive themselves to be more effective than others perceive themselves to be.

Our model uses mean fee and mean coinsurance data, and we, therefore, assume that price and coinsurance are constant. We think this is a strong but not unreasonable assumption. Like the studies previously referenced, our patients have been treated by a single provider, but unlike the previous studies, both in- and out-patient treatment was possible. Further, outpatient care could have taken place in any one of a variety of settings and sometimes for very long periods. We are unaware of studies that have analyzed changes in price and coinsurance over the entire range of actual treatment experiences. Clearly, as treatment progresses net price could either rise or fall. It is possible that, on average, one direction offsets the other over the entire course of treatment; in fact, some of our preliminary but unpublished work tends to support this possibility. As a first approximation, we believe that it is reasonable to neglect this problem.

\section{RESULTS}

As described in Table 4, estimates of the model are generally good for the first two equations; for the drug and termination equations, however, the results are disappointing. The value of an estimated $R^{2}$, calculated from the residuals, is between 0.05 and 0.41 for the duration of treatment equation, and between 0.21 and 0.57 for the improvement equation. When compared to the sample values found in Table 2, the model underpredicts the hours of treatment for psychiatrists and psychologists. However, once some very large outliers were eliminated, the resulting sample averages were very close to the model estimates.

\section{Determinants of hours of treatment and patient improvement}

Coefficients in the hours of treatment equation are mostly consistent with expectations. The longest durations of treatment are associated with patients who terminate "normally"; however, this association is significant only for psychiatrists and social workers. As expected, inpatient treatment is an important component of psychiatrists' services; indeed, this is the only provider group where percentage of time devoted to inpatient settings is significant. For all provider groups, hours of treatment is unaffected by provider caseload. No evidence was found to suggest hours of treatment varies much by setting; the work-setting coefficients do not have consistent signs and are usually not significant. Female providers tend to be associated with longer treatment periods, as are providers whose treatment methods are strongly influenced by psychoanalytic theory. Finally, with one exception, patients who achieve more improvement are found to have remained longer in treatment.

For the improvement equation, the patient's initial severity is the main predictor of improvement. The coefficient is highly significant across all providers and diagnosis groups. The relation between health status and duration of treatment resembles a logistic function over the relevant range. Longer treatments are associated with more improvement, although the coefficient is not significant 
Table 4. Estimation results

\begin{tabular}{|c|c|c|c|c|c|c|c|c|c|c|c|c|}
\hline \multirow[b]{3}{*}{ Variable } & \multicolumn{6}{|c|}{ Anxiety, personality and neurosis } & \multicolumn{6}{|c|}{ Relationship problems } \\
\hline & \multicolumn{2}{|c|}{ Psychiatrists } & \multicolumn{2}{|c|}{ Psychologists } & \multicolumn{2}{|c|}{ Social workers } & \multicolumn{2}{|c|}{ Psychiatrists } & \multicolumn{2}{|c|}{ Psychologists } & \multicolumn{2}{|c|}{ Social workers } \\
\hline & Coef. & $T^{*}$ & Coef. & $T^{\bullet}$ & Coef. & $T^{\prime}$ & Coef. & $T^{*}$ & Coef. & $T^{*}$ & Coef. & $T^{\prime}$ \\
\hline \multicolumn{13}{|c|}{ Length of treatment equation } \\
\hline $\begin{array}{l}\text { CONSTANT } \\
\text { IMPROV } \\
\text { TERM } \\
\text { PATINCOM } \\
\text { PATINP\% } \\
\text { NFEE } \\
\text { TOT \# PAT } \\
\text { PRIOFF } \\
\text { PUBLIC } \\
\text { FEE\%INC } \\
\text { PROSEX } \\
\text { PRO\%PSYCH }\end{array}$ & $\begin{array}{r}0.74841 \\
0.05852 \\
0.72002 \\
-0.00017 \\
-0.01033 \\
-0.00046 \\
-0.00142 \\
-0.01753 \\
0.26959 \\
0.00229 \\
-0.40677 \\
0.01343 \\
\end{array}$ & $\begin{array}{l}1.47 \\
3.94 \\
3.44 \\
0.13 \\
2.34 \\
0.24 \\
1.30 \\
0.06 \\
0.72 \\
0.73 \\
1.47 \\
3.55 \\
\end{array}$ & $\begin{array}{r}1.12196 \\
0.04685 \\
0.08326 \\
0.00474 \\
0.00326 \\
-0.00300 \\
-0.00005 \\
-0.13171 \\
0.21748 \\
0.00224 \\
-0.25844 \\
0.01316\end{array}$ & $\begin{array}{l}3.22 \\
5.05 \\
0.61 \\
1.96 \\
1.17 \\
1.28 \\
0.04 \\
0.55 \\
0.74 \\
0.93 \\
1.96 \\
6.58\end{array}$ & $\begin{array}{r}0.77958 \\
0.05178 \\
0.72344 \\
0.00562 \\
-0.00495 \\
-0.00867 \\
0.00149 \\
-0.03852 \\
0.13998 \\
0.00099 \\
-0.13985 \\
0.00331 \\
\end{array}$ & $\begin{array}{l}2.05 \\
5.10 \\
3.45 \\
1.45 \\
1.12 \\
1.67 \\
0.84 \\
0.13 \\
0.50 \\
0.32 \\
0.76 \\
0.87\end{array}$ & $\begin{array}{r}1.65900 \\
0.02329 \\
0.64865 \\
-0.00010 \\
-0.00575 \\
-0.00257 \\
0.00014 \\
-0.17750 \\
-0.91634 \\
0.00107 \\
-0.37034 \\
0.00330 \\
\end{array}$ & $\begin{array}{l}2.99 \\
2.69 \\
2.35 \\
0.09 \\
0.75 \\
0.60 \\
0.09 \\
0.46 \\
1.88 \\
0.29 \\
1.18 \\
0.72\end{array}$ & $\begin{array}{r}2.41737 \\
-0.02221 \\
-0.06671 \\
0.00020 \\
-0.00403 \\
-0.00741 \\
-0.00079 \\
0.45478 \\
0.24471 \\
-0.00065 \\
-0.20913 \\
0.00675\end{array}$ & $\begin{array}{l}7.14 \\
3.59 \\
0.45 \\
0.08 \\
0.82 \\
2.87 \\
0.66 \\
1.74 \\
0.67 \\
0.25 \\
1.47 \\
2.83\end{array}$ & $\begin{array}{r}1.02172 \\
0.03568 \\
0.65122 \\
-0.00136 \\
-0.00287 \\
-0.01253 \\
-0.00396 \\
0.57920 \\
-0.23324 \\
-0.00149 \\
0.05485 \\
0.01137\end{array}$ & $\begin{array}{l}3.35 \\
3.73 \\
3.17 \\
0.70 \\
0.54 \\
2.58 \\
2.09 \\
2.18 \\
1.00 \\
0.53 \\
0.30 \\
3.48\end{array}$ \\
\hline \multicolumn{13}{|c|}{ Production function equation } \\
\hline $\begin{array}{l}\text { CONSTANT } \\
\text { LOT } \\
\text { LOT**2 } \\
\text { ISEV } \\
\text { DRUG' } \\
\text { ISEV }{ }^{*} \text { DRUG } \\
\text { PATAGE } \\
\text { TOT\%NEU } \\
\text { PROEXPER } \\
\text { PATINP\% } \\
\dot{\sigma}_{\| 1}^{b} \\
\bar{\sigma}_{22} \\
\dot{\rho}^{\prime} \\
\text { AH R2 LOT } \\
\text { AH R2 IMPROV } \\
\text { NSDT } \\
\end{array}$ & $\begin{array}{r}30.00874 \\
0.02593 \\
-0.00001 \\
-0.44489 \\
-5.68976 \\
-0.10491 \\
0.12373 \\
0.05334 \\
0.19002 \\
0.04949 \\
1.95 \\
248.91 \\
-0.49 \\
0.31 \\
0.26 \\
2 \\
\end{array}$ & $\begin{array}{l}4.37 \\
1.90 \\
1.70 \\
4.49 \\
0.74 \\
1.65 \\
1.38 \\
1.21 \\
1.58 \\
1.05\end{array}$ & $\begin{array}{r}48.51223 \\
0.00500 \\
-0.00000 \\
-0.39796 \\
-0.60935 \\
-0.03526 \\
-0.02028 \\
-0.07967 \\
-0.10434 \\
-0.02442 \\
1.13 \\
174.64 \\
0.06 \\
0.41 \\
0.21 \\
2 \\
\end{array}$ & $\begin{array}{r}11.28 \\
0.31 \\
0.32 \\
7.90 \\
0.08 \\
1.20 \\
0.27 \\
2.51 \\
1.13 \\
0.68\end{array}$ & $\begin{array}{r}39.90975 \\
0.14006 \\
-0.00051 \\
-0.55627 \\
-12.37822 \\
0.30887 \\
-0.07165 \\
-0.00093 \\
0.38102 \\
0.10209 \\
1.25 \\
168.79 \\
-0.36 \\
0.37 \\
0.38 \\
4\end{array}$ & $\begin{array}{l}5.93 \\
1.90 \\
1.93 \\
6.07 \\
1.38 \\
1.74 \\
0.71 \\
0.02 \\
2.87 \\
2.07\end{array}$ & $\begin{array}{r}55.03670 \\
0.55736 \\
-0.00293 \\
-0.62004 \\
6.38643 \\
-0.06423 \\
-0.10091 \\
-0.03308 \\
-0.00776 \\
-0.08022 \\
1.24 \\
130.50 \\
-0.43 \\
0.22 \\
0.57 \\
5 \\
\end{array}$ & $\begin{array}{l}6.73 \\
3.60 \\
3.22 \\
7.10 \\
0.68 \\
0.96 \\
0.99 \\
0.65 \\
0.06 \\
1.04\end{array}$ & $\begin{array}{r}37.41476 \\
0.01 ! 19 \\
-0.00020 \\
-0.29389 \\
23.56770 \\
-0.48998 \\
0.01641 \\
-0.02813 \\
-0.10607 \\
-0.04949 \\
1.99 \\
154.82 \\
0.70 \\
0.05 \\
0.22 \\
3\end{array}$ & $\begin{array}{c}10.28 \\
0.29 \\
2.27 \\
7.11 \\
2.03 \\
1.85 \\
0.33 \\
1.05 \\
1.42 \\
1.13\end{array}$ & $\begin{array}{r}32.80589 \\
0.20192 \\
-0.00045 \\
-0.42838 \\
28.30507 \\
-0.55939 \\
0.09747 \\
-0.01267 \\
0.03141 \\
0.01758 \\
1.05 \\
92.46 \\
-0.41 \\
0.31 \\
0.48 \\
4\end{array}$ & $\begin{array}{l}7.47 \\
3.45 \\
2.82 \\
8.30 \\
2.70 \\
2.69 \\
1.33 \\
0.41 \\
0.35 \\
0.36\end{array}$ \\
\hline \multicolumn{13}{|c|}{ Drug use equation } \\
\hline $\begin{array}{l}\text { CONSTANT } \\
\text { PATAGE } \\
\text { PATAGE*22 } \\
\text { TOT \# PAT } \\
\text { PUHLIC } \\
\text { PRO\%PSYCH } \\
\text { E(PROD DRUG) }\end{array}$ & $\begin{array}{r}-2.98140 \\
0.23101 \\
-0.00233 \\
0.00263 \\
0.76543 \\
-0.02008 \\
0.25401\end{array}$ & $\begin{array}{l}1.19 \\
2.13 \\
1.82 \\
1.31 \\
1.30 \\
2.59 \\
2.28\end{array}$ & $\begin{array}{r}0.25462 \\
0.00182 \\
-0.00007 \\
0.00538 \\
0.78053 \\
-0.00856 \\
1.04790\end{array}$ & $\begin{array}{l}0.12 \\
0.02 \\
0.05 \\
1.76 \\
1.29 \\
1.30 \\
3.22\end{array}$ & $\begin{array}{r}-2.57930 \\
0.01545 \\
0.00002 \\
0.00429 \\
0.93018 \\
-0.00251 \\
-0.03864\end{array}$ & $\begin{array}{l}1.00 \\
0.12 \\
0.01 \\
1.03 \\
1.90 \\
0.27 \\
0.76\end{array}$ & $\begin{array}{r}-2.67730 \\
-0.04079 \\
0.00061 \\
0.00336 \\
1.11650 \\
-0.01459 \\
0.61618\end{array}$ & $\begin{array}{l}0.70 \\
0.27 \\
0.38 \\
0.97 \\
1.10 \\
1.06 \\
1.98\end{array}$ & $\begin{array}{r}-12.68400 \\
0.32446 \\
-0.00314 \\
0.00609 \\
-23.98700 \\
0.01178 \\
0.15789\end{array}$ & $\begin{array}{l}1.82 \\
1.05 \\
0.85 \\
0.85 \\
0.01 \\
0.78 \\
2.74\end{array}$ & $\begin{array}{r}-67.98900 \\
2.99310 \\
-0.03720 \\
0.02051 \\
1.56860 \\
0.02258 \\
1.17530\end{array}$ & $\begin{array}{l}2.18 \\
1.98 \\
1.95 \\
2.19 \\
1.45 \\
0.93 \\
2.24\end{array}$ \\
\hline \multicolumn{13}{|c|}{ Reason for termination of treatment equation } \\
\hline $\begin{array}{l}\text { CONSTANT } \\
\text { DRUG' }^{\prime} \\
\text { PATSEX } \\
\text { FEE\%PATY } \\
\text { AVMINVIS } \\
\text { PRIOFF } \\
\text { PRIOFF-ISEV }\end{array}$ & $\begin{array}{r}1.57670 \\
-0.59618 \\
0.17368 \\
-0.10213 \\
-0.01095 \\
-0.71406 \\
0.00300\end{array}$ & $\begin{array}{l}2.19 \\
1.52 \\
0.52 \\
1.41 \\
0.79 \\
1.02 \\
0.25\end{array}$ & $\begin{array}{r}0.58646 \\
-0.05965 \\
-0.10001 \\
-0.17084 \\
0.00398 \\
-0.99886 \\
0.01598\end{array}$ & $\begin{array}{l}0.75 \\
0.17 \\
0.44 \\
0.92 \\
0.30 \\
1.97 \\
1.92\end{array}$ & $\begin{array}{r}0.20970 \\
-0.05784 \\
0.57647 \\
-0.93505 \\
0.01248 \\
0.07166 \\
-0.01030\end{array}$ & $\begin{array}{l}0.17 \\
0.11 \\
1.44 \\
1.25 \\
0.54 \\
0.08 \\
0.70\end{array}$ & $\begin{array}{r}-0.13320 \\
0.15763 \\
0.00046 \\
0.67523 \\
0.01774 \\
2.69043 \\
-0.04011\end{array}$ & $\begin{array}{l}0.09 \\
0.20 \\
0.01 \\
0.76 \\
0.58 \\
1.83 \\
1.96\end{array}$ & $\begin{array}{r}0.71088 \\
0.18972 \\
0.22705 \\
-0.54480 \\
-0.00552 \\
-0.19650 \\
0.00863\end{array}$ & $\begin{array}{l}0.91 \\
0.21 \\
0.88 \\
1.67 \\
0.46 \\
0.31 \\
0.95\end{array}$ & $\begin{array}{r}0.99959 \\
1.57850 \\
0.03198 \\
-0.77163 \\
0.00807 \\
-0.07873 \\
-0.00835\end{array}$ & $\begin{array}{l}0.78 \\
1.15 \\
0.08 \\
2.03 \\
0.35 \\
0.08 \\
0.56\end{array}$ \\
\hline $\bar{N}$ & 174 & & 363 & & 152 & & 89 & & 279 & & 152 & \\
\hline
\end{tabular}

"Absolute value of " $t$-stat".

"The äs have been adjusted to yield unbiased estimates following the recommendation of Bard [3].

'An ad hoc $R^{2}$ for the LOT equation derived from MLE residuals.

¿Same as above, but with IMPROV.

'Number of significant digits in $t$-stat. (Applies to the first three equations only.)

'The DRUG variable refers only to psychoactive agents in the case of psychiatrists, and it refers to any drugs in the case of psychologists and social workers.

IPROD DRUG = productivity of drug in treatment.

in the case of psychologists. Psychologists with more experience report less improvement in health status for their patients than do those with less experience. We have no convincing explanation for this result beyond speculation that more experienced psychologists may take on less tractable patients. Finally, alternative treatment settings does not appear to have a significant impact on the outcome of treatment.

\section{Probability of drug usage and termination type}

It is hardly surprising that drugs are more likely to be used in those cases for which their expected productivity is high. Drug treatment is greatest for patients in the vicinity of $50 \mathrm{yr}$ of age, and, of course, it is much less for patients with mild diagnoses. 
Table 5. Price, income and insurance elasticities of the length of treatment

\begin{tabular}{|c|c|c|c|c|c|c|}
\hline \multirow[b]{2}{*}{ Disorder } & \multicolumn{2}{|c|}{ Psychiatrists } & \multicolumn{2}{|c|}{ Psychologists } & \multicolumn{2}{|c|}{ Social workers } \\
\hline & $\eta$ & Time" & $\eta$ & Time" & $\eta$ & Time" \\
\hline \multicolumn{7}{|c|}{ Fee elasticity of the LOT } \\
\hline $\begin{array}{l}\text { NEURO } \\
\text { RELAT }\end{array}$ & $\begin{array}{r}-0.0273 \\
-0.0816 \\
\end{array}$ & $\begin{array}{r}-1.03 \\
-1.00 \\
\end{array}$ & $\begin{array}{r}-0.0935 \\
-0.2372 \\
\end{array}$ & $\begin{array}{r}-2.22 \\
-2.79 \\
\end{array}$ & $\begin{array}{r}-0.2814 \\
-0.3277 \\
\end{array}$ & $\begin{array}{r}-4.80 \\
-4.23 \\
\end{array}$ \\
\hline \multicolumn{7}{|c|}{ Income elasticity of the LOT } \\
\hline $\begin{array}{l}\text { NEURO } \\
\text { RELAT } \\
\end{array}$ & $\begin{array}{r}-0.0022 \\
-0.0505 \\
\end{array}$ & $\begin{array}{r}-0.08 \\
-0.62 \\
\end{array}$ & $\begin{array}{l}0.1362 \\
0.0062\end{array}$ & $\begin{array}{l}3.23 \\
0.07 \\
\end{array}$ & $\begin{array}{r}0.2051 \\
-0.0151 \\
\end{array}$ & $\begin{array}{r}3.50 \\
-0.20\end{array}$ \\
\hline \multicolumn{7}{|c|}{ Insurance $(\%)$ elasticity of the LOT } \\
\hline $\begin{array}{l}\text { NEURO } \\
\text { RELAT }\end{array}$ & $\begin{array}{l}0.0273 \\
0.0881\end{array}$ & $\begin{array}{l}1.03 \\
1.08 \\
\end{array}$ & $\begin{array}{l}0.0937 \\
0.2285\end{array}$ & $\begin{array}{l}2.22 \\
2.69\end{array}$ & $\begin{array}{l}0.1870 \\
0.2373\end{array}$ & $\begin{array}{l}3.19 \\
3.07\end{array}$ \\
\hline
\end{tabular}

The elasticities were computed by taking the partial derivative of LOT with respect to (Fee, Income, and Insurance $\%$ ) not holding IMPROV and TERM constant. The elasticities must be interpreted as being "expected" values thereof. The Monte-Carlo method was not applied here; it would not have made much sense. The elasticities allowing $\partial \mathrm{TERM} / 2 \mathrm{VAR}=0$ (VAR $=$ fee, etc.) and $\partial$ IMPROV $/ \partial L O T=0$ did not differ significantly from the values shown above.

"The value "time" stands for the change in LOT (in min) in response to an increase in fees, income. and insurance in each of the respective boxes above. For example, an increase of $1 \%$ in fees for a psychiatrist's NEURO patients will on average result in a reduction of 1.03 min of treatment. The percentage change in insurance is somewhat complicated to interpret. It refers to the percentage change of the insurance coverage which is already measured in percentage terms, eg. a change in coverage from 50 to $60 \%$ is a $20 \% \Delta$ increase in coverage.

The termination equation has no generally consistent or significant coefficients. Both this and the drug equation are presented for the sake of completeness, and because drug use and the reason for termination are plausible components of our study on theoretical grounds. It is possible that these equations would have been more successful if more fine-grained categories had been available to us. As it is, however, because their results are so unimpressive, these two equations will not be considered further.

\section{Hours of treatment elasticities}

Net fees are inversely related to length of treatment in all versions of our model, satisfying the expected condition that increases in fees tend to reduce lengths of treatment while increases in insurance tend to increase them. Statistically, however, this relationship is very weak; of the six coefficients relating net fee to treatment hours, only two meet minimal criteria for statistical significance. Nevertheless, by using the values of the coefficients in Table 4 and the average sample values found in Table 2, we computed the implied elasticities (Table 5). All of these elasticities are extremely small; none exceed 0.33 (in absolute value), and half of them are below 0.10 . In short, our data reveal no significant relationships between net fees or patient income and hours of treatment.

The net fee coefficient is largest for social workers and psychologists, and the elasticity with respect to fees or insurance coverage is largest for social workers (Table 5). Therefore, to the extent that fees, insurance coverage, or patient income do affect hours of treatment, the effect is greater on the patients of social workers and psychologists than on the patients of psychiatrists.

\section{Comparative productivity of alternative care providers}

As described earlier, we employed a Monte-Carlo method to obtain estimates of the dependent variables for each provider group in order to compare their relative effectiveness. Using this procedure, we examined hypothetical cases where members of one provider group treat patients that might otherwise have been treated by another provider group. The object of this exercise is to determine any cost-benefit advantages that might be realized in transferring patients from one provider group to another. This procedure implicitly assumes that patients do not differ significantly across provider groups in characteristics not reflected in our data and that the decision 
Table 6. Simulation results describing provider performance

\begin{tabular}{|c|c|c|c|c|c|c|}
\hline \multirow{2}{*}{$\begin{array}{l}\text { Provider } \\
\text { group }\end{array}$} & \multicolumn{2}{|c|}{$\begin{array}{l}\text { Patients of } \\
\text { psychiatrists }\end{array}$} & \multicolumn{2}{|c|}{$\begin{array}{l}\text { Patients of } \\
\text { psychologists }\end{array}$} & \multicolumn{2}{|c|}{$\begin{array}{l}\text { Patients of } \\
\text { social workers }\end{array}$} \\
\hline & Mear & SD & Mean & $\mathrm{SD}$ & Mean & SD \\
\hline \multicolumn{7}{|c|}{ Anxiety. neurosis and personality disorders (NEURO) } \\
\hline $\begin{array}{l}\text { Psychiatrists } \\
\text { LOT } \\
\text { IMPROV } \\
\text { DRUG } \\
\text { TERM } \\
\text { COST } \\
\text { ISEV } \\
\text { FSEV" }\end{array}$ & $\begin{array}{r}41.20 \\
16.71 \\
0.22 \\
0.66 \\
3542.38 \\
51.07 \\
67.78\end{array}$ & $\begin{array}{r}67.91 \\
18.82 \\
0.41 \\
0.48 \\
7410.97 \\
17.05 \\
19.31 \\
\end{array}$ & $\begin{array}{r}42.34 \\
16.48 \\
0.23 \\
0.66 \\
3615.65 \\
50.45 \\
66.93\end{array}$ & $\begin{array}{r}69.79 \\
18.17 \\
0.42 \\
0.47 \\
8236.64 \\
15.04 \\
18.99 \\
\end{array}$ & $\begin{array}{r}41.90 \\
16.15 \\
0.23 \\
0.65 \\
3635.90 \\
50.30 \\
66.46 \\
\end{array}$ & $\begin{array}{r}70.24 \\
18.47 \\
0.42 \\
0.48 \\
7810.71 \\
15.05 \\
19.09 \\
\end{array}$ \\
\hline $\begin{array}{l}\text { LOT } \\
\text { IMPROV } \\
\text { DRUG } \\
\text { TERM } \\
\text { COST } \\
\text { ISEV } \\
\text { FSEV }\end{array}$ & $\begin{array}{r}31.68 \\
20.15 \\
0.11 \\
0.63 \\
010.78 \\
50.06 \\
70.20\end{array}$ & $\begin{array}{r}51.25 \\
14.91 \\
0.31 \\
0.48 \\
3480.13 \\
16.71 \\
16.78 \\
\end{array}$ & $\begin{array}{r}31.56 \\
20.37 \\
0.10 \\
0.64 \\
2016.27 \\
50.50 \\
70.87\end{array}$ & $\begin{array}{r}51.88 \\
14.72 \\
0.30 \\
0.48 \\
441.47 \\
15.12 \\
16.21\end{array}$ & $\begin{array}{r}31.47 \\
20.39 \\
0.11 \\
0.63 \\
1998.41 \\
50.26 \\
70.65 \\
\end{array}$ & $\begin{array}{r}52.91 \\
14.86 \\
0.31 \\
0.48 \\
3518.69 \\
15.18 \\
16.04 \\
\end{array}$ \\
\hline $\begin{array}{l}\text { LOT } \\
\text { IMPROV } \\
\text { DRUG } \\
\text { TERM } \\
\text { COST } \\
\text { ISEV } \\
\text { FSEV" }\end{array}$ & $\begin{array}{r}26.68 \\
18.29 \\
0.16 \\
0.71 \\
040.29 \\
50.55 \\
68.84\end{array}$ & $\begin{array}{r}16.84 \\
0.36 \\
0.45 \\
709.50 \\
16.41 \\
16.11 \\
\end{array}$ & $\begin{array}{r}26.53 \\
18.43 \\
0.15 \\
0.71 \\
015.30 \\
50.03 \\
68.46\end{array}$ & $\begin{array}{r}38.11 \\
16.62 \\
0.35 \\
0.45 \\
623.76 \\
15.25 \\
17.75 \\
\end{array}$ & $\begin{array}{l}1 \\
2 \\
5 \\
2 \\
2 \\
3 \\
5\end{array}$ & $\begin{array}{r}37.19 \\
16.41 \\
0.36 \\
0.45 \\
581.15 \\
14.69 \\
15.48 \\
\end{array}$ \\
\hline \multicolumn{7}{|c|}{ Relationship problems (RELAT) } \\
\hline $\begin{array}{l}\text { LOT } \\
\text { IMPROV } \\
\text { DRUG } \\
\text { TERM } \\
\text { COST } \\
\text { ISEV } \\
\text { FSEV }\end{array}$ & $\begin{array}{r}18.35 \\
19.72 \\
0.12 \\
0.70 \\
505.10 \\
61.17 \\
80.49\end{array}$ & $\begin{array}{r}25.75 \\
17.85 \\
0.35 \\
0.46 \\
2195.67 \\
17.15 \\
13.01\end{array}$ & $\begin{array}{r}18.66 \\
20.24 \\
0.14 \\
0.71 \\
520.51 \\
60.30 \\
80.54\end{array}$ & $\begin{array}{r}26.01 \\
17.28 \\
0.34 \\
0.45 \\
204.74 \\
15.84 \\
12.92\end{array}$ & $\begin{array}{r}18.74 \\
20.25 \\
0.13 \\
0.71 \\
1540.34 \\
59.95 \\
80.20\end{array}$ & $\begin{array}{r}26.18 \\
17.45 \\
0.34 \\
0.45 \\
2248.45 \\
16.35 \\
13.01\end{array}$ \\
\hline $\begin{array}{l}\text { LOT } \\
\text { IMPROV } \\
\text { DRUG } \\
\text { TERM } \\
\text { COST } \\
\text { ISEV } \\
\text { FSEV }\end{array}$ & $\begin{array}{r}18.15 \\
16.13 \\
0.01 \\
0.68 \\
1155.93 \\
61.05 \\
77.18\end{array}$ & $\begin{array}{r}27.76 \\
13.57 \\
0.09 \\
0.46 \\
1878.57 \\
17.81 \\
17.43\end{array}$ & $\begin{array}{r}17.86 \\
16.53 \\
0.01 \\
0.69 \\
1119.74 \\
59.92 \\
76.45\end{array}$ & $\begin{array}{r}27.17 \\
13.35 \\
0.11 \\
0.46 \\
1776.61 \\
15.96 \\
16.60\end{array}$ & $\begin{array}{r}17.21 \\
16.30 \\
0.01 \\
0.69 \\
1076.17 \\
60.15 \\
76.45 \\
\end{array}$ & $\begin{array}{r}26.97 \\
13.23 \\
0.09 \\
0.46 \\
1732.14 \\
15.76 \\
16.51 \\
\end{array}$ \\
\hline $\begin{array}{l}\text { LOT } \\
\text { IMPROV } \\
\text { DRUG } \\
\text { TERM } \\
\text { COST } \\
\text { ISEV } \\
\text { FSEV }\end{array}$ & $\begin{array}{r}22.40 \\
14.80 \\
0.08 \\
0.77 \\
845.14 \\
61.72 \\
75.80\end{array}$ & $\begin{array}{r}40.02 \\
15.28 \\
0.27 \\
0.42 \\
1688.58 \\
16.94 \\
12.72\end{array}$ & $\begin{array}{r}23.96 \\
15.14 \\
0.09 \\
0.77 \\
907.70 \\
59.83 \\
74.97\end{array}$ & $\begin{array}{r}43.10 \\
15.11 \\
0.28 \\
0.42 \\
1802.03 \\
15.70 \\
12.30\end{array}$ & $\begin{array}{r}23.42 \\
15.01 \\
0.08 \\
0.77 \\
880.26 \\
59.63 \\
74.64\end{array}$ & $\begin{array}{r}41.95 \\
15.38 \\
0.27 \\
0.42 \\
1771.35 \\
16.43 \\
12.49\end{array}$ \\
\hline
\end{tabular}

'FSEV $=$ final severity of the condition.

of the patient to seek treatment is independent of the provider type. + The results are found in Table 6 .

The main fact to note from Table 6 is that patient characteristics do not differ significantly by provider group. Regarding the diagnosis cluster for the anxiety, neurotic, and personality disorders, it is evident that, on average, psychiatrists are associated with a longer duration of treatment than are the other provider groups. The psychiatrists' cost of treatment for this cluster is three times that imposed by social workers. Focusing on improvement units (measured in terms of change in initial severity) per hour of treatment, psychiatrists do not compare well with the alternative providers; the ratio of mean health status improvement per hour is $0.41,0.65$, and 0.73 for

†An additional problem is the fact that the coefficients for the duration of treatment variables are not significant for the production function for psychologists. Nevertheless, we used these values; consequently, the associated estimates are rough. We are reassured about proceeding in this fashion because the values for the psychologists' coefficients fall neatly between the values found for psychologists and social workers. 
psychiatrists, psychologists, and social workers, respectively. If we calculate the average ratio of cost to improvement we obtain 212,99 , and $\$ 55$ for psychiatrists, psychologists, and social workers, respectively. The ratios of cost to treatment duration are 86,64 , and $\$ 39$, respectively. Compared to other providers, psychiatrists have a longer average duration of treatment, and their patient improvement rates are relatively poor.

In the case of relationship disorders, the relative effectiveness of psychiatrists is greater: for the three provider types, respectively, the ratios of improvement to duration are 1.05, 0.93, and 0.64; the ratios of cost to improvement: 78,68 , and $\$ 59$; and the ratios of cost to duration: 82,63 , and \$36. With this diagnosis group the psychiatrists compare favorably in terms of improvement per unit of treatment, although when the cost is taken into account, the psychiatrists' comparative cost advantage is still not as great as that of the other providers.

\section{CONCLUSIONS}

Of fundamental concern to any economic analysis of mental health services is the cost-effectiveness of service providers. Issues of this sort have been difficult to address, however, because of the lack of adequate comparative data describing both providers and their patients. To the best of our knowledge, the Mental Health Service Providers Survey dataset is the first that makes possible a comparison of provider effectiveness while taking into account many significant patient characteristics.

The diagnostic categories investigated by this study are relatively mild, so there is no serious medical barrier to treatment of these patients by any of the mental health specialists considered. We do not expect, for example, that patients with marital problems who choose to see a social worker differ much from those that choose to see a psychiatrist. Moreover, we were able to control for many of the possible sources of difference, such as the patient's initial severity, age, sex, income, and insurance coverage, because variables reflecting these factors are included in our model.

These and other controls employed by this study permit comparisons across provider groups and give us considerable confidence in the conclusion that in the cases of patients with relatively mild mental problems, efficiency gains may be found from reallocating patients from psychiatrists to psychologists and social workers. The cost ratios we have calculated reveal important differences among these providers. When both cost and improvement are considered, psychiatrists appear to be the least efficient providers and social workers the most. Moreover, these cost advantages do not seem to entail any impairment in the quality of treatment. (However, work in progress indicates that psychiatrists are much more cost-effective in treating patients with more severe conditions.) An economically efficient mental health provision system must take these differences into account.

Of course, simulations are inherently limited because it is impossible to account fully and accurately for every important real-world relationship. For this reason, a key implication of this study is that there is a need for randomized clinical trials to assess the differential performance outcomes of services provided by alternative provider groups on patients with similarly mild conditions. Studies of this nature would serve to further clarify the substitution issues considered by the present investigation. In the absence of such trials, our results provide a basis for the implications discussed below.

Insurance companies, state insurance regulatory boards, and health personnel planning groups should encourage provider substitution as a cost-cutting measure. A logical place to start would be insurance incentives. With few exceptions, providers receive reimbursements regardless of the treated condition; reimbursement formulas are often similar for such diverse problems as marital discord and schizophrenia. On the other hand, substitution in the direction of increased efficiency is becoming easier. In most states, freedom-of-choice laws give mental health specialists independent status, making psychologists and (in many states) social workers eligible to receive third-party reimbursements without physician supervision. It is clear from our results that such laws promote an efficient allocation of resources, and that they should be encouraged. At the moment, however, these laws do not take into account the patient's condition. Our study suggests that diagnostic category should be taken into account so that treatment of the less severe mental and emotional conditions can be reimbursed at lower rates than that of severe mental illness. 
Further implications for mental health insurance are suggested by the elasticities associated with duration of treatment. Among all mental disorders, the diagnostic classes described in this study are the mildest. They therefore offer the consumer the most discretion in choosing treatment and should show the greatest price responsiveness. For this reason, the small effect of net fees or patient income on hours of treatment is an important finding. It suggests that consumer responsiveness to variations in gross fee or insurance coverage must be confined largely to the decision to seek treatment rather than the decision to prolong treatment. The relative insensitivity of duration of treatment to income and fees indicates that variations in fees and insurance will affect mostly the numbers of patients seeking treatment. Thus, somewhat more generous reimbursements, especially for outpatient care, would be likely to encourage consumer entry but not to affect hours of treatment.

Our research also sheds some light on the common assertion that providers affected by increased competition will attempt to compensate for the associated loss in income by encouraging their patients to undergo further treatment. We searched for such a relationship by using caseload as a proxy for the demand facing the provider. Changes in caseload did not alter treatment duration perceptibly; only social workers treating patients with relationship problems seemed to shorten duration of treatment when faced with an increased demand.

We also might expect that providers who receive a salary would be less likely to encourage lengthy treatment than would others who work mostly on a fee-for-service basis. Our results fail to support this assertion as well. None of the coefficients reflecting the importance of fee in the provider's income was statistically significant. In short, we found no evidence to support the "supply-induced demand" or "target income" hypotheses.

The fact that initial severity is the most influential explanatory variable in our model suggests that it might make a significant difference to the overall cost of the mental health system, as well as to the general level of mental health across a population, if it were possible to get patients into the health care system before their mental health status had deteriorated to the extent that it does now. A full analysis of this question is beyond the scope of the current article, but it is relatively straightforward to use our model to simulate a provision system in which all patients enter treatment with lower initial severity. This would provide a partial indication of the benefits of such "early intervention". A simulation of our model with initial severity scores $20 \%$ higher (i.e. less impaired) than those actually reported in our data set produces costs and time in treatment that are $20 \%$ below the original values, with final health status improved by 5-10 points.

Finally, this study has implications for the development of prospective payment systems for the financing of mental health care. In general, such payment systems are based on statistical models that use patient attributes to predict the average treatment resources they will consume. The present Medicare prospective payment system uses the patient's principal and secondary diagnoses to predict consumption of hospital resources. In mental health, these simple models do not have much predictive power, and for this reason, many mental health units in hospitals are exempt from this program and thus continue to be cost-reimbursed. Many policymakers would prefer mental health outpatient services to be reimbursed on a prospective basis, but this extension faces similar barriers.

The current study provides a preliminary indication of how one might develop a prospective reimbursement scheme for mental health services. Our model demonstrates how to use the characteristics of the patient, the provider, and the treatment setting to estimate the hours of treatment, cost, and the concurrent improvement in the patient's condition. With this information in hand, payment schedules could be adjusted to incorporate both cost control and improvement objectives. The same sort of model makes it possible to obtain global use and cost estimates for any given distribution of patient characteristics. These estimates are essential ingredients when planning for the efficient operation of health maintenance organizations, community mental health centres, and similar major mental health facilities. Given our model's limitations, it cannot, in its present form, serve as a basis for payment of planning decisions. However, we believe the model does offer a basic structure capable of sustaining further building and refinement. Of course, the model is complicated, reflecting the uncertainties and complexities of present forms of mental health care. Whether a model of this kind will have the necessary political appeal to be adopted thus remains an open question. 
Acknowledgements - This research was supported by U.S. Public Health Service Grants MHI6413, MH38378 and MH41212 and by funds from the state of Michigan.

\section{REFERENCES}

1. American Psychiatric Association. Diagnostic and Statistical Manual of Mental Disorders, Third Edn. Revised. American Psychiatric Association, Washington. D.C. (1987).

2. P. Balch. J. F. Ireland and S. B. Lewis. Fees and therapy: relation of source of payment to course of therapy at CMHC. J. consult. clin. Psychol. 45(3), 504 (1977).

3. Y. Bard. Nonlinear Parameter Estimation. Academic Press. New York (1974).

4. P. J. Carpenter and L. M. Range. The effects of patients' fee payment source on the duration of outpatient psychotherapy. J. clin. Psychol. 39(2). 304-306 (1983).

5. J. S. Cramer. Econometric Applications of Maximum Likelihood Methods. Cambridge University Press, New York (1986).

6. J. Endicott, R. L. Spitzer, J. L. Fleiss and J. Cohen. The global assessment scale: a procedure for measuring overall severity of psychiatric disturbance. Archs gen. Psychiat. 33(6), 766-771 (1976).

7. S. M. Goldfeld and R. E. Quandt. Nonlinear simultaneous equations: estimation and prediction. Int. Econ. Rev. 9(1). $112-136(1968)$.

8. M. C. Hombrook, A. V. Hurtado and R. E. Johnson. Health care episodes: definition, measurement and use. Med. Care Rer. 42(2), 163-218 (1985).

9. E. B. Keeler. K. B. Wells. W. G. Manning. J. D. Rumpel and J. M. Hanley. The Demand for Episodes of Mental Health Services. The Rand Corporation. Santa Monica. Calif. (1986).

10. D. J. Knesper, B. E. Belcher and J. G. Cross. Preliminary production functions describing change in mental health status. Med. Care 25(3), 222-237 (1987).

11. D. J. Knesper. B. E. Belcher and J. G. Cross. A market analysis comparing the practices of psychiatrists and psychologists. Archs gen. Psychiat. 46, 305-314 (1989).

12. D. J. Knesper and D. J. Pagnucco. Accuracy of provider-supplied human resources data. Am. Psychol, 39(12), $1485-1486(1984)$.

13. D. J. Knesper and D. J. Pagnucco. Estimated distribution of effort by providers of mental health services to U.S. adults in 1982 and 1983. Am. J. Psychiat. 144(7), 883-888 (1987).

14. D. J. Knesper, D. J. Pagnucco and N. M. Kalter. Agreement on patient diagnosis, treatment, and referral across provider groups. Prof. Psychol. 17(4). 331 -337 (1986).

15. D. J. Knesper, D. J. Pagnucco and J. R. Wheeler. Similarities and differences across mental health services providers and practice settings in the United States. Am. Psychol. 40(12), 1352-1369 (1985).

16. G. S. Maddala. Limited-Dependent and Qualitative Variables in Econometrics. Cambridge University Press, New York (1983).

17. W. G. Manning. C. N. Morris, J. P. Newhouse and L. L. Orr et al. A two-part model of the demand for medical care: preliminary results from the health insurance study. Health, Economics, and Health Economics (Edited by J. van der Gaag and M. Perlman), pp. 103-123. North-Holland, Amsterdam (1980).

18. R. S. Mariano and B. W. Brown. Asymptotic behavior of predictors in a nonlinear simultaneous-equations case. Imt. Econ. Rev. 24, 523-536 (1983).

19. P. A. R. May. Cost-effectiveness of mental health care: sex as a parameter of cost in the treatment of schizophrenia. Am. J. publ. Hith 60(12), 2269-2272 (1970).

20. T. G. McGuire. Financing Psychotherapy. Ballinger Press, Cambridge, Mass. (1981).

21. B. A. Murtagh and M. A. Saunders. MINOS: a large-scale nonlinear programming system. Technical Report SOL 77. Systems Optimization Laboratory, Stanford University, Calif. (1977).

22. K. S. Pope, J. D. Geller and L. Wilkinson. Fee assessment and outpatient psychotherapy. J. consull. clin. Psychol. 43, 835-841 (1975).

23. P. Schmidt. Estimation of a simultaneous equations model with jointly dependent continuous and qualitative variables: the union-earnings question revisited. Int. Econ. Rev. 19(2), 453-465 (1978).

24. W. H. Silverman and R. P. Beech. Length of intervention and client-assessed outcome. J. clin. Psychol. 40(2), 453-465 (1984).

25. S. Sue, H. L. McKinney and B. J. Burns. Predictors of the duration of therapy for clients in the community mental health system. Community Ment. H/th J. 12(4), 365-375 (1976).

26. C. A. Taube, L. G. Kessler and B. J. Burns. Estimating the probability and level of ambulatory mental health services. Hith Sens Res. 21(2), 321-340 (1986).

27. K. B. Wells, W. G. Manning. N. Duan, J. E. Ware and J. P. Newhouse. Cost Sharing and the Demand for Ambulatory Mental Health Serices. The Rand Corporation, Santa Monica, Calif. (1982). 